\title{
Comunidade urbana: segundo José Comblin e a sociologia de Zygmunt Bauman
}

\author{
Urban community: \\ according to José Comblin and \\ sociology of Zygmunt Bauman
}

Jefferson Grijó Brasil ${ }^{1}$

Resumo: A nova cultura se define como urbana, e esse questionamento é o que temos desenvolvido neste trabalho desde o início, expondo a urbe como algo central e determinante no cristianismo, com a intenção de sugerir pistas e direções para a comunidade cristã na vida citadina.

Palavras-chave: José Comblin. Vida urbana e comunidade.

Abstract: The new culture is defined as urban, and this question is what we have developed in this work from the beginning, exposing the metropolis as something central and decisive in Christianity, with the intention to suggest clues and directions to the Christian community in the city life.

Keywords: José Comblin. Urban life and community.

\section{Introdução}

A humanidade sempre esteve associada ao outro. Essa questão é ontológica: o ser humano vive na reciprocidade. O relacionamento faz parte da sua natureza. Comblin diz: "Se a pessoa humana somente existe no intercâmbio com outras pessoas, se ela se conhece, aprende e se desenvolve olhando para o rosto dos outros,

Artigo recebido em: 26 jun. 2016 Aprovado em: 28 nov. 2018

${ }^{1}$ Doutorando em Teologia pela PUC-Rio, Mestre em Ciências das Religiões pela Faculdade Unida de Vitória-ES. 
esses outros onde estariam, se não fosse na cidade?"2. A cidade proporciona um ótimo cenário para essa representação de vida humana, com muitas tentativas narradas na história. A interdependência de outros pode nos permitir desenvolver aqui o conceito de comunidade na urbe. Para Comblin, "a cidade não é apenas o vínculo que une os indivíduos e suas associações, o vínculo dos intercâmbios e da comunicação de onde procede a liberdade, é também uma comunidade, uma comunidade global"3. Para esse autor, o comunitarismo ilustra a vida urbana e suas costuras em laços de humanização, definindo-a como global.

Mas mesmo que a comunidade urbana seja de fato comunitarismo, Comblin não a vê como homogênea. É justamente o contrário: ele acredita que "a cidade tem personalidade. Cada uma tem seu caráter" 4 . Sendo singular, cada comunidade urbana realça seu modo de ser comunitária, pois a comunidade se define como tal por reunir em si elementos específicos de pessoas com os mesmo indicativos. Logo, o mundo global é constituído de várias comunidades urbanas, e não de uma comunidade uniforme. Comblin assegura que "a pertença à cidade é fenômeno comparável à pertença à família ou ao povo" 5 . O indivíduo faz parte de uma determinada família, e tal modelo exemplifica de maneira simples a pista que Comblin segue em seu conceito de comunidade urbana, que, para ele, "é muito diferente da pertença a associações secundárias ou voluntárias. Expressa-se no orgulho que todo cidadão sente por sua cidade" 6 . Ele entende a comunidade urbana ontologicamente como inseparável do indivíduo residente na urbe. $\mathrm{O}$ fator está diretamente ligado à questão geográfica do espaço urbano delimitado a certo grupo alcançado. Para ele, "só o fato de viver em uma mesma cidade basta para formar comunidades e sentimento de pertença"7. A ideia de comunidade destacada nos textos de Comblin tem a ver com a comunidade inserida dentro da cidade, podendo ser definida como essência da urbe. Sem ela a vida citadina se tornaria um caos sem limites. E ainda, segundo ele, "a tristeza procede da solidão da pessoa sobre o desgaste da luta cotidiana" ${ }^{\text {. Só restariam }}$ as marcas dos atritos em forma de tristeza da vida solitária em meio a tantos.

\footnotetext{
${ }^{2}$ COMBLIN, José. Antropologia cristã. Petrópolis: Vozes, 1985, p. 135.

3 COMBLIN, José. Teologia da cidade. São Paulo: Paulinas, 1991, p. 176.

4 COMBLIN, 1991, p. 176.

5 COMBLIN, 1991, p. 176.

${ }^{6}$ COMBLIN, 1991, p. 176.

7 COMBLIN, 1991, p. 176.

${ }^{8}$ COMBLIN, José. A oração de Jesus. São Paulo: Paulus, 2010, p. 99.
} 


\section{O sucesso comunitário segundo Comblin}

Ainda em tempos atuais se torna intrigante o que faz com que a cidade tenha sucesso. Apontamos que seja literalmente o laço comunitário que une e completa o sentido de vida: "A comunidade representa o homem novo face a todos os individualismos e todos os totalitarismos sociais, sejam eles eclesiásticos, civis ou militares"9. A superação do rompimento do individualismo apresenta-se como novidade, mas Comblin vai mais longe:

O que constitui o vínculo comunitário da cidade? Diz-se que é a memória coletiva. De fato, a cidade é uma espécie de memória coletiva, memória depositada nas pedras e nas dimensões. As pedras contam sucessos vividos em comum, que afetaram destino comum. ${ }^{10}$

Na verdade a construção social de tudo o que a coletividade habilitar veio a ser a atração na perspectiva da vida citadina. Assim a história é escrita e suas memórias fixadas, como também seu modo de ser. O que acontecia com frequência em tempos passados é que a função de ajuntar as pessoas na cidade era da religião. Assim, Comblin lembra: "Nas cidades mais antigas, os templos foram, com frequência, os que desempenharam essa missão"11. Segundo o autor a religião desempenhou essa função, que define a ideia de vida na urbe como o senso comunitário. Portanto, na maioria das cidades antigas o templo ocupava lugar de destaque, o que leva à definição de Comblin: "A religião representava o papel de condensadora do espírito da cidade e a estilizava" ${ }^{12}$. Nessa estilização, que se vê constatada ainda na contemporaneidade, podem-se notar certos traços da religião nos espaços na urbe. Se ela foi instrumento de ajuntamento na cidade, ela tem parte na história e nas memórias da cidade, portanto constitui o movimento urbano. Comblin também examina o exemplo das cidades gregas: "A cidade grega já não se contentou com seus templos. Acrescentou a ágora, o teatro, o estádio, três lugares destacados da consciência da cidade" ${ }^{13}$. Podemos nos arriscar a dizer que a centralidade da essência de

\footnotetext{
9 COMBLIN, 1985, p. 25.

${ }^{10}$ COMBLIN, 1991, p. 176.

${ }^{11}$ COMBLIN, 1991, p. 177.

12 COMBLIN, 1991, p. 177.

${ }_{13}$ COMBLIN, 1991, p. 177.
} 
ajuntamento não é alterada, apenas desenvolvida de outras formas. Tanto o teatro como o templo e o estádio proporcionam momentos de encontro social aos residentes na urbe, além do espetáculo. Os três recebem grande destaque na consciência da cidade, segundo o autor. Comblin ainda exemplifica como isso acontece em Roma: "Em Roma foram o fórum e o circo. Como os templos, também, todos esses lugares servem para representação que a cidade se dá a si mesma" ${ }^{14}$. Nesse caso são acrescentados o fórum e o circo, mas os pontos comuns entre as cidades gregas e romanas são os templos. É muito importante esse esclarecimento, pois demonstra claramente o envolvimento religioso na cultura urbana. Não se trata aqui da forma romântica religiosa, mas de fatos. Comblin continua:

Na Idade Média havia de um lado a catedral, que servia ao mesmo tempo de bolsa, de teatro, de palácio, de fórum e de lugar de reunião; do outro, havia a praça. Esta se manteve até nossos dias. As grandes praças são testemunhas de acontecimentos importantes vividos em comum. ${ }^{15}$

A evolução apresentada pelo autor dos lugares de ajuntamento que representam a coletividade, de templos a praças, no percurso histórico da urbe, aponta para um forte equilíbrio ao afirmar que a religião, naquela época ainda prematura e obscura, já ensinava aos homens sua necessidade de comunitarismo na urbe.

Mas também se manifesta na história das comunidades um paradoxo presente exatamente num momento em que as cidades presenciaram grandes mudanças em suas estruturas. $\mathrm{O}$ autor argumenta: "Além disso, as cidades da era industrial paleotécnica assistiram às grandes fraturas da comunidade. As cidades se partiram"16. Na perspectiva de Comblin, as cidades se partiram por causa da degradação das comunidades, pois a vida humana basicamente depende da associação a outros. Afinal, "a existência humana é necessariamente comunitária"17. Ele acredita que são os vínculos comunitários que proporcionam gestos de humanidade na cidade, e sem eles esta seria um espaço frio e fadada a terminar. Por isso ele apontou, como vimos, que as cidades se extinguiram por causa da crise instaurada na vida comunitária. Em determinado tempo, essa condição não foi respeitada e não se pode perder de

\footnotetext{
${ }_{14}$ COMBLIN, 1991, p. 177.

15 COMBLIN, 1991, p. 177.

${ }^{16}$ COMBLIN, 1991, p. 178

${ }_{17}$ COMBLIN, José. O caminho: ensaio sobre o seguimento de Jesus. 2 ed.

São Paulo: Paulus, 2004, p. 200.
} 
vista que "o modo de viver comunitário cria novas personalidades e enriquece em todos os pontos de vista"18.

O enfraquecimento dos vínculos comunitários traz consequências danosas: o ser humano urbano passava a maior parte do cotidiano envolvido nas atividades industriais. Submetido a essa demanda, não lhe sobrava o tempo necessário para a vida comunitária, o que, segundo o autor, culminou com o fracasso da cidade nesse momento da história. Essa corrente na vida citadina conduz a outra questão. A dissociação da burguesia de todo tipo de vida comunitária de que participa a massa a leva a criar mecanismos que demonstrem certa aparência de vida comunitária própria. Um exemplo desse movimento foi o surgimento da ópera, inserida na vida citadina da burguesia, que, segundo Comblin, vivia "tentando esquecer a existência do proletariado"19. E criando, dessa forma, suas opções seletivas de comunitarismo, no qual não havia possibilidade de vida comum entre todos, mesmo que residissem na mesma cidade. Ele acrescenta: "Mas todos os lugares em que a burguesia tentava fingir que vivia a vida da cidade proclamavam demais que se tratava de lugares privados, símbolos de classe" 20 . O que se estabelece com essas construções seletivas para determinada parcela da urbe, a fim de forçar laços humanos de comunitarismo, serve apenas para dissociar classes e mostrar a fragmentação da comunidade urbana. Para Comblin, "este cisma ainda não foi superado" ${ }^{21}$. Ainda se podem constatar, como sempre, as divisões na cidade que fragmentam a vida em comunidade. Todos os lugares que, de algum modo, apontam para o comunitarismo se localizam nos centros. Na visão de Comblin, "os lugares destacados tradicionais das cidades ocidentais se fundem nos centros comerciais" 22 .

\section{Os centros lugar de comunidade?}

Os lugares que visam ao ajuntamento de pessoas estão inseridos em centros comerciais, em uma combinação que se mostra pragmática na urbe. Porém, nas cidades contemporâneas, tem se firmado a supremacia das atividades comerciais nos centros,

${ }^{18}$ COMBLIN, José. O Espírito Santo e a libertação. Petrópolis: Vozes, 1987, p. 47.

19 COMBLIN, 1991, p. 178.

${ }^{20}$ COMBLIN, 1991, p. 178.

${ }^{21}$ COMBLIN, 1991, p. 178.

${ }^{22}$ COMBLIN, 1991, p. 178 
relegando os vínculos comunitários a posição secundária. O autor descreve a situação com desencanto: "Resta ver os centros de nossas grandes cidades nos domingos e dias de festa. Dão a impressão de cidades mortas" 23 . Sim, parece que definitivamente o centro perdeu a essência de comunidade urbana, mas, não obstante o pessimismo de sua observação, Comblin admite: "Os centros têm antes de tudo função de diálogo, de reunião, de representação" 24 .

Mesmo que o centro não represente a totalidade de comunitarismo, ele ainda é sede de decisões que envolvem a vida de todos os habitantes da urbe. Essa representação tem a ver com o projeto de comunidade, que precisa fazer sentido, e isso acontece com maior sucesso por meio da criatividade e de encontros: "A vida exige um projeto. Quando uma sociedade não tem mais projeto de vida, ela perde a vitalidade, enfraquece, torna-se uma sociedade aborrecida, que não se sente chamada a fazer mais nada e perde a criatividade" 25 .

O centro tem se tornado cada vez mais um lugar de reuniões de diálogos em torno de questões que permeiam a cidade, como também tem sido um lugar de protestos e manifestações, ou seja, nos centros ainda existem encontros, mesmo que não sejam tão cotidianos. Comblin destaca: "Uma coisa é certa: se os centros desaparecem ou transformam-se em cidade administrativa ou comercial, ou também em museus, como nas antigas cidades europeias, a cidade está condenada a morrer" ${ }^{26}$. Ele defende claramente a função comunitária do centro. Além disso, toca em um ponto crucial na contemporaneidade, os meios de comunicações, crendo firmemente que essa difusão, sem precedentes na história humana, tem proporcionado o fracasso do comunitarismo na vida citadina:

Não podemos crer que os meios de comunicação social, meios de contato a distância, possam substituir os centros. Esses meios proporcionam espetáculos inertes, em que os ouvintes e os espectadores não são de modo algum atores. A cidade, porém, é espetáculo em que cada um deve tomar sua parte. ${ }^{27}$

23 COMBLIN, 1991, p. 178.

24 COMBLIN, 1991, p. 179.

${ }_{25}$ COMBLIN, José. A vida: em busca da liberdade. São Paulo: Paulus, 2007, p. 77-78.

26 COMBLIN, 1991, p. 179.

27 COMBLIN, 1991, p. 179. 
Grande defensor da cidade como comunidade urbana, Comblin vê os entretenimentos midiáticos como ópio, destruidor dos laços comunitários. Para ele, essa máquina de divertir torna tudo fictício, distante, servindo apenas para distração e negando ao habitante da urbe a oportunidade de ser participante do espetáculo real no comunitarismo que a cidade oferece. Tornado mero telespectador ou participante virtual, ele perde o calor humano. "As épocas de maior vitalidade foram as épocas em que uma sociedade tinha um projeto coletivo. Suscitava o entusiasmo de todos" ${ }^{28}$. Comblin reconhece que as cidades atuais são grandes desafios. Ele conclui:

O problema crucial das cidades de hoje e do futuro reside em como organizar a reunião material e concreta dos cidadãos. Pois é evidente que os modelos do passado não são aptos para as grandes massas das cidades novas. ${ }^{29}$

O desafio de oferecer um comunitarismo coerente e atual com a finalidade de que os habitantes da cidade desfrutem da essência que pulsa na urbe, ou seja, dos vínculos humanos, revela-se decisivo. A cidade já está sob grande ameaça, prestes a perder o sentido. Comblin alerta: "Durante a quase totalidade da sua história, o que uniu as comunidades foram os laços de sangue, e estes permanecem até hoje na sociedade paralela, embora a família esteja muito enfraquecida" ${ }^{\circ}$. O comunitarismo está, desde o início, enraizado na humanidade e dela faz parte. Em suma, o homem é comunidade.

\section{A comunidade segundo Zygmunt Bauman}

O sociólogo Zygmunt Bauman reconhece o respeito a que as comunidades fazem jus, dado que, como fato social, estão presentes no cotidiano e cumprem importante papel na atribuição de sentido ao homem. Tento que reconhece certa comoção na temática e nunca lhe foi indiferente:

Há comoção em torno da necessidade de comunidade principalmente porque é cada vez menos claro se as realidades que os retratos da

\footnotetext{
${ }^{28}$ COMBLIN, 2007. p. 78.

29 COMBLIN, 1991, p. 179.

${ }^{30}$ COMBLIN, 2004, p. 200.
} 
"comunidade" afirmam representar são evidentes, e, se, caso possam ser encontradas, merecerão ser tratadas, em vista da expectativa de sua duração, com o respeito que exigem. ${ }^{31}$

Para nos darmos conta de que a comunidade se torna fato social na urbe, basta verificar sua inserção na vida, uma vez que ela não é um fenômeno esporádico ou de ocorrência incerta. O que acontece com as comunidades é que elas se reinventam e se adaptam à realidade de cada cidade, o que não lhes permite a uniformidade. Bauman afirma:

A valente defesa da comunidade e a tentativa de restaurar sua posição negada pelos liberais dificilmente teriam acontecido se não fosse pelo fato de que os arreios com os quais as coletividades atam seus membros a uma história conjunta, ao costume, linguagem e escola, ficam mais esgarçados a cada ano que passa. $3^{2}$

Segundo Bauman, a defesa da comunidade se dá em torno de certa busca do lugar que ela perdeu na sociedade diante dos liberais, por isso ela costura tudo o que pode com a finalidade de atar seus membros. Ele acrescenta: "As comunidades vêm em várias cores e tamanhos, mas, se colocadas num eixo weberiano que vai de 'leve manto' a 'gaiola de ferro', aparecerão todas notavelmente próximas do primeiro polo"33. Como já foi afirmado antes, a contextualização de cada comunidade se faz de acordo com as condições de sua inserção. Nada de muito novo se apresenta no quesito comunidade urbana, mas ela se faz presente, como sempre. Para Bauman, "a comunidade 'tal como aparece nas pinturas comunitárias' poderia ser suficiente tangível para ficar invisível e permitir o silêncio; mas os comunitários não pintam suas semelhanças, e muito menos as exibem" 34 . No comunitarismo segundo Bauman, o porvir sempre fica para depois, em um segundo estágio. Primeiro se projeta o presente, por isso grande parte das ocupações em vida comunitária não proporciona algo tangível, pois os comunitários não o fazem com muita questão de mostrar, e menos ainda por não se tratar de semelhanças ou uniformidade.

${ }^{31}$ BAUMAN, Zygmunt. Modernidade líquida. Rio de Janeiro: Zahar, 2001, p. 211.

32 BAUMAN, 2001, p. 210.

33 BAUMAN, 2001, p. 212.

34 BAUMAN, 2001, p. 212. 
Bauman crê que as pistas de que se serve o sociólogo definir um importante fato social devem ser sua crescente popularidade, e eis nessa emergência de opiniões a importância da comunidade como objeto de um trabalho que ofereça explicação e compreensão. Ele diz:

Para o sociólogo, no entanto, o que constitui um
importante fato social que merece ser
explicado/compreendido é a própria popularidade
(talvez crescente) das ideias comunitárias
(enquanto o fato de que o disfarce tenha sido tão
bom a ponto de não obstruir o sucesso comunitário
não melindraria muito, sociologicamente falando -
é corriqueiro demais). .35

Em uma análise sociológica do comunitarismo, Bauman o vê como reação diante das rápidas transformações decorrentes da atualidade. Sendo assim, o feito da comunidade se justifica como o confronto do ser humano com incertezas, mais do que com certezas, e o sucesso comunitário faz sentido por ser a comunidade detentora da projeção de um futuro. Bauman prossegue:

Em termos sociológicos, o comunitarismo é uma
reação esperável à acelerada "liquefação" da vida
moderna, uma reação antes acima de tudo ao
aspecto da vida sentido como a mais aborrecida e
incômoda entre suas numerosas consequências
penosas - crescente desequilíbrio entre a liberdade
e as garantias individuais. ${ }^{36}$

O comunitarismo se manifesta como febre, apontando para algo de errado no organismo social, pois representa a defesa contra o desgaste do ser diante do convívio em um tempo de fragilidade, sem garantias de segurança - em todos os sentidos da vida - e de liberdade. Bauman continua: "Um aspecto muito visível do desaparecimento das velhas garantias é a nova fragilidade dos laços humanos"37. Como já não são duráveis as estruturas que regem a vida em sociedade, e muito menos nos laços humanos, e como a vida social simples e pura sem traços religiosos não preenche eficazmente essa lacuna permanente na sociedade, abre-se então a possibilidade de um renascimento comunitário. Segundo Bauman, "o comunitarismo renascido responde à questão genuína e pungente de

\footnotetext{
35 BAUMAN, 2001, p. 212.

36 BAUMAN, 2001, p. 212-213.

37 BAUMAN, 2001, p. 213.
} 
que o pêndulo oscila radicalmente - e talvez para longe demais afastando-se do polo da segurança na díade dos valores humanos fundamentais" 38 . O comunitarismo proporciona esse paradoxo na sociedade, mesmo que muitos sociólogos já tenham previsto seu fim há muito tempo, apoiando-se, para fundamentar essa previsão, justamente na urbanização. Ela parece resistir e se adaptar, adquirindo novas cores e tamanhos. Essa flexibilidade da comunidade talvez seja a fonte de sua resistência - não por acaso Bauman afirma: "Por essa razão, o evangelho comunitário tem uma grande audiência"39.- ao proporcionar novas maneiras de se apresentar diante da sociedade, que tem se tornado cada vez mais obscura e cheia de incertezas. O comunitarismo oferece auxílio e respostas a esses desafios que permeiam a vida urbana. É ainda Bauman que assegura:

as perspectivas incertas na velhice e os infortúnios da vida urbana como as principais fontes da difusa ansiedade em relação ao presente, ao dia de amanhã e ao futuro mais distante: a falta de segurança é o que une as três, e o principal apelo do comunitarismo é a promessa de um ponto seguro. [...]. $4^{40}$

Aparentemente incoerente diante de tanta modernidade, o comunitarismo, para muitos sociólogos, é utopia que atrasa o homem ou o prede, impossibilitando-o de alcançar a liberdade. Outros ainda afirmam que se trata de um velho ópio, mas de um modo ou de outro resiste e ainda assim não foi superado: "A comunidade do evangelho comunitário é um lar evidente. [...] e um tipo de lar, por certo, que para a maioria das pessoas é mais como um belo conto de fadas que uma experiência pessoal" 41 .

$\mathrm{O}$ quadro mostrado pelo próprio Zygmunt Bauman mostra que, por mais que à luz da Sociologia o comunitarismo seja algo infantil, ele aponta algo romântico e esperançoso para os olhos de uma sociedade desanimada: "A harmonia interior do mundo comunitário brilha e cintila contra a escura e impenetrável selva que começa no outro lado da estrada"42. Foi definido antes, no início desta sessão, que a comunidade só se constitui como tal ajuntando indivíduos de indicativos comuns, e que cada comunidade tem

$3^{8}$ BAUMAN, 2001, p. 213.

39 BAUMAN, 2001, p. 213.

40 BAUMAN, 2001, p. 213.

41 BAUMAN, 2001, p. 214.

42 BAUMAN, 2001, p. 215. 
identidade própria, distinguindo-se de outra e mostrando-se avessa à uniformidade. Bauman examina ainda essa questão: "Uma 'comunidade includente' seria uma contradição em termos" 43 . Se ela fosse totalmente aberta perderia seu comunitarismo, tornando-se apenas uma sociedade que vive na urbe, porém aqui seguimos a ideia de que as comunidades não só integram a cidade, como peças de um mosaico, mas são a sua essência.

\section{Conclusão}

Mesmo que as previsões caminhem para uma secularização da sociedade em termos públicos, a religião continuará a ter lugar no privado e o ser humano continuará a buscá-la: "A sociedade pode estar secularizada ou laicizada na vida pública, mas isso não exclui que a religião tenha forte presença na vida privada" 44 . E isso se comprova cada vez mais nos dias atuais. Como já citado antes, se o ser humano na urbe não se contenta apenas com as estruturas oferecidas pela cidade, isso já causa fratura. Existe a necessidade de vínculos em forma de comunidade, em qualquer que seja $o$ segmento, e aqui destacamos o modelo comunitário de igreja, pois “o ser humano vive em relação à totalidade e não se contenta com uma existência limitada ao visível, ao sensível"45. Ele busca a experiência com outra coisa, e mesmo diante da concretude estabelecida na cidade, em um momento de fuga, o homem se volta à experiência do sagrado, que ele precisa atingir. Conclui-se então que "a comunidade cristã está ligada à cidade" 46 . E a cidade ligada à comunidade.

\section{Referências}

COMBLIN, José. Antropologia cristã. Petrópolis: Vozes, 1985.

COMBLIN, José. O Espírito Santo e a libertação. Petrópolis: Vozes, 1987.

COMBLIN, José. Teologia da cidade. São Paulo: Paulinas, 1991.

COMBLIN, José. O caminho: ensaio sobre o seguimento de Jesus. 2 ed. São Paulo: Paulus, 2004.

\footnotetext{
43 BAUMAN, 2001, p. 215.

44 COMBLIN, 2004, p. 212.

45 COMBLIN, 2004, p. 212.

46 COMBLIN, 1985, p. 135.
} 
COMBLIN, José. A vida: em busca da liberdade. São Paulo: Paulus, 2007.

COMBLIN, José. A oração de Jesus. São Paulo: Paulus, 2010.

BAUMAN, Zygmunt. Modernidade líquida. Tradução de Plínio Dentzien. Rio de Janeiro: Zahar, 2001. 